\title{
Prevalence of Dental Fluorosis in Mianwali and Mardan Districts
}

\author{
Komal Siddiq ${ }^{*}$, Suman Dost, Ayesha Naseem, Ammara Arshad, Atta Ullah \\ Riphah Internarional University, Islamic International Dental College, Islamabad, Pakistan. \\ Email: *kool.kat66@hotmail.com
}

Received June $2^{\text {nd }}, 2011$, revised July $5^{\text {th }}, 2011$; accepted July $20^{\text {th }}, 2011$.

\begin{abstract}
This study was conducted to assess the level of dental flourosis and Decaying, Missing, Filled Tooth (DMFT) of selected patients, in district Mardan village Rustam and District Mianwali village Harnoli. Study was conducted among people of age 10 - 60 years. The regions of Rustam and Harnoli are known to have high value of fluoride in drinking water. A cross sectional study was conducted among the subjects and the grade of fluorosis was calculated according to Deans Fluorosis Index. DMFT of each subject was also calculated. Total of 100 subjects were selected by simple random sampling technique among the population of Rustam and Harnoli and they were observed for the extent of fluorosis they had along with the number of decayed, missing and filled teeth they had Most of the population uses underground water, the water people commonly used was collected and was tested for amount of fluoride. The results show that there is a strong relationship between fluoride level and extent of fluorosis. Populations of both areas have dental fluorosis due to high concentration of fluoride in drinking water and also comparatively low DMFT because fluoride has caries protective effect.
\end{abstract}

Keywords: Prevalence, Fluorosis, DMFT

\section{Introduction}

Dental fluorosis is defined as the disturbance in development of dental enamel; this is caused by excessive amount of fluoride exposure during development, which results in enamel with lower mineral content and increased porosity. The fluoride ion comes from the element fluorine. Fluorine, the 17th most abundant element in the earth's crust, is a gas and never occurs in a free state in nature. It exists only in combination with other elements as fluoride compounds, which are constituents of minerals in rocks and soil. Fluoride exists in both ionic and bound forms in plasma, with the bound form being present in larger quantity. Fluoride concentrations in human saliva are slightly less than those found in Plasma, ranging from 0.01 to $0.05 \mathrm{ppm}$. Severity of dental fluorosis depends on when and for how long the overexposure to fluoride occurs, the individual response, weight, degree of physical activity, nutritional factors and bone growth, suggesting that dose of fluoride may lead to different levels of dental fluorosis. Esthetic changes in permanent dentition are greatest concern in dental fluorosis, which are more prone to occur in children who are excessively exposed to systemic and topical fluoride be- tween 20 to 30 months of age. Safe level for daily fluoride intake is $0.05-0.07 \mathrm{mg} \mathrm{F} / \mathrm{kg} / \mathrm{day}$. It has been observed from different researches that tea, pan, tobacco and fluorinated toothpastes also play some role in cause of dental fluorosis. In Pakistan mostly underground water is used for drinking, so high fluoride content in water may adversely affect the dental aesthetics of people of the area with high water fluoride levels. Hence the present work has been carried out to find out the effect of fluoride rich water and dentifrices on prevalence of fluorosis in district Mardan, and district Mianwali [1-5].

\section{Materials and Methods}

A cross-sectional study was conducted in district Mianwali, village Harnoli and district Mardan, village Rustam, to evaluate prevalence of fluorosis. The regions of $\mathrm{Ru}-$ stam and Harnoli are known to have high value of fluoride in drinking water. A questionnaire was designed and was filled out by examining the subjects and by asking them questions regarding their eating habits, tobacco chewing, daily tea consumption, oral hygiene habits and type of dentifrices they use. The subjects consisted of age 10 - 60 years. Examination aids used were tongue de- 
pressors, disposable gloves and hand held torch. Fluorosis was detected by Dean's Fluorosis Index and the data collected and calculated was statistically analyzed by Chi-square test .The criteria i.e. Deans Fluorosis Index, upon which we graded, our subjects are given in Table $\mathbf{1 .}$

\section{Results}

\subsection{District Mianwali Village Harnoli}

The results demonstrate $98 \%$ prevalence of fluorosis in Mianwali. Out of 100 subjects selected for the study 41 were males and 59 were females. Severe degradation on labial surface of anterior teeth was observed among the subjects. The subjects had age between 12 - 60 years.

\subsubsection{Mean DMFT}

The mean DMFT of the population surveyed was calculated to be 3.3 in district Mianwali.

\subsubsection{Prevalence of Fluorosis}

Prevalence of fluorosis in district Mianwali is given in Figure 1.

Hence only $2 \%$ of the subjects showed no signs of fluorosis, while rest $98 \%$ showed a certain pattern of fluorosis.

\subsubsection{Association between Socio-Economic Status \& Oral Health}

The chi-square value for association between socioeconomic status and oral health situation was calculated to be 0.027 in Mianwali.

Table 1. Deans fluorosis index.

\begin{tabular}{|c|c|}
\hline $\mathbf{0}$ & $\begin{array}{l}\text { Normal: The enamel surface is smooth, glassy and } \\
\text { usually a pale creamy-white color. }\end{array}$ \\
\hline 0.5 & $\begin{array}{l}\text { Questionable: The enamel shows slight aberrations } \\
\text { from the translucency of normal enamel, few white } \\
\text { flecks to few spots. }\end{array}$ \\
\hline 1 & $\begin{array}{l}\text { Very Mild: Small, opaque, paper white areas scat- } \\
\text { tered irregularly over the tooth but involving less } \\
\text { than } 25 \% \text { of the labial tooth surface. }\end{array}$ \\
\hline 2 & $\begin{array}{l}\text { Mild: The white opacity of the enamel of the teeth } \\
\text { is more extensive than for code } 2 \text {, but covers less } \\
\text { than } 50 \% \text { of the tooth surface. }\end{array}$ \\
\hline 3 & $\begin{array}{l}\text { Moderate: The enamel surface of the teeth show } \\
\text { wear and brown stain is frequently a disfiguring } \\
\text { feature. }\end{array}$ \\
\hline 4 & $\begin{array}{l}\text { Severe: The enamel surface hypoplasia marked } \\
\text { with pitted areas and brown stains the teeth often } \\
\text { have a corroded appearance. }\end{array}$ \\
\hline $\mathbf{X}$ & Excluded: e.g. crowned tooth. \\
\hline 9 & Not-Recorded. \\
\hline
\end{tabular}

\subsubsection{Association between Liquids Consumed Daily and Fluorosis}

The water samples were tested in Pakistan Council of research in Water Resources (PCRWR). The water of district Mianwali had fluoride level $1.59 \mathrm{ppm}$. All the subjects told that they consumed tea twice daily which equals to $1 / 2$ liter consumption daily since tea also has fluoride in its ingredients so the fluoride of water along with that of tea both enhances fluorosis.

\subsubsection{Psychological Effects}

It was found that fluorosis is not only a cosmetic defect but it also has certain psychological impact. People with severe fluorosis were found to be less social, less happy and less hygienic.

\subsection{District Mardan Village Rustam}

The subjects from rural area of Mardan were taken for examination. Their ages varied between 10 - 40. It is proved from researches that tea also contains fluoride in it, thus daily consumption of 1 liter tea gives the body amount of fluoride that is comparable to that of recommended value but the routine increase tea intake enhanced the effect of fluorosis.

\subsubsection{Mean DMFT}

The mean DMFT of the population surveyed was calculated to be 2.06 in district Mardan; this low value of DMFT strengthens the fact that fluoride has a protective effect on teeth's vitality by making them carious resistant.

\subsubsection{Prevalence of Fluorosis}

The number of people and the grade of fluorosis they had in district Mardan are given in Figure 2.

This figure shows that only $15 \%$ subjects showed no signs of fluorosis, while remaining $85 \%$ showed a certain pattern of fluorosis.

\subsubsection{Association between Socio-economic Status \& Oral Health}

The chi-square value for association between socioeconomic status and oral health situation was calculated to be 0.012 in Mardan.

\subsubsection{Association between Liquids Consumed Daily and Fluorosis}

The water of district Mardan was found fluoride level to be $1.02 \mathrm{ppm}$. All the subjects told that they consumed tea twice daily which equals to $1 / 2$ liter consumption daily since tea also has fluoride in its ingredients so the fluoride of water along with that of tea both enhances fluorosis.

\section{Discussion}

Dental fluorosis is an irreversible staining and mottling of 
enamel, caused by excessive amounts of fluoride during tooth development (birth-5 years) [6], so it was seen that mothers who spent the duration of their pregnancy in Mianwali and Mardan, their babies had white opaque spots on anterior teeth which proves that fluoride effects the primary teeth bud formation at the stage when enamel is forming.

In very mild to moderate cases of fluorosis it was seen that fluorosis is beneficial in a way that fluorotic enamel was caries resistant than normal enamel. However in moderate and severe fluorosis, teeth are susceptible to caries as enamel is structurally weak because of stainig and pitting, [7] as shown in the Table 2 which is based on the results obtained from district Mianwali:

Most of the subjects had DMFT of 2 - 3, that was due to unavailability of proper dental health care services and lack of knowledge about general dental health among the people of district Mianwali and Mardan, otherwise the remaining dentition had no sign of caries and that was because of high fluoride intake, but brown spots spoiling the aesthetics of subject was seen in majority.

It is proved from researches that tea also contains fluoride in it as shown in Table 3.

Thus daily consumption of 1 liter of tea gives our body the amount of fluoride that is comparable to that of the recommended value. All of our subjects consumed tea approximately $1 / 2$ liter daily but they were already consuming a lot of fluoride through their drinking water along with this an average person receives fluoride from additional sources other than water like fluorinated oral hygiene products, food and beverages processed by

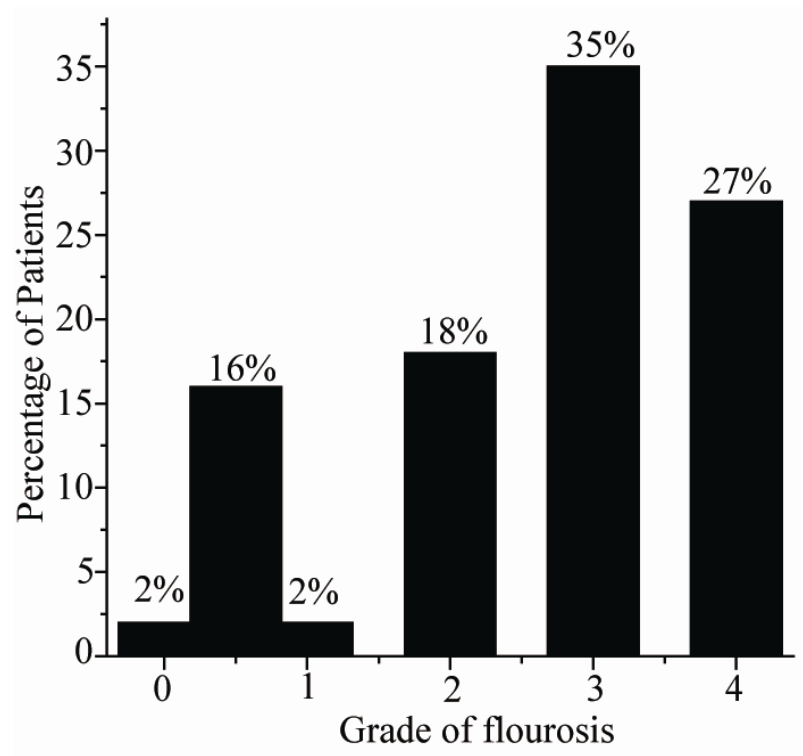

Figure 1. Percentage of patients that come under specific grade of fluorosis in village Harnoli.



Figure 2. Percentage of patients that come under specific grade of fluorosis in village Rustam.

Table 2. The percentage of patients having very mild-mild fluorosis and their mean DMFT and the percentage of patients having moderate-severe fluorosis and their mean DMFT.

\begin{tabular}{ccc}
\hline & Percentage (\%) & Mean DMFT \\
\hline Very mild-mild & 20 & 2 \\
Moderate-Severe & 72 & 5 \\
\hline
\end{tabular}

Table 3. Amount of fluoride in different types of teas.

\begin{tabular}{ccc}
\hline Type of Tea & Fluoride (mg/liter)* & Fluoride (mg/8 ounces) \\
\hline Green & $1.2-1.7$ & $0.3-0.4$ \\
Oolong & $0.6-1.0$ & $0.1-0.2$ \\
Black & $1.0-1.9$ & $0.2-0.5$ \\
Brick tea & $2.2-7.3$ & $0.5-1.7$ \\
\hline
\end{tabular}

fluorinated water and teas [8,9]. This additional ingestion of fluoride was found to enhance fluorosis.

\section{REFERENCES}

[1] J. A. Alvarez, K. Mayra, P. C. Rezende, S. M. S. Marocho, F. B. T. Alves, P. Celiberti and A. L. Ciamponi, "Dental Fluorosis, Exposure, Arevention and Management," Journal of Clinical and Experimental Dentistry, Vol. 1, No. 1, 2009, pp. e14-e18.

[2] C. R. M. D. Rodrigues, A. C. D. Ramires-Romito and C. G. D. C. Zardetto, “Abordagem Edcative Preventia em Odontopediatria,” In: R. J. A. Cardoso and E. A. N. Gonclaves, Odontopediatria, Arte Ciencia, Sao Paulo, 2002, pp. 113136.

[3] B. A. Burt, "The Changing Patterns of Systemic Fluoride Intake,” Journal of Dental Research, Vol. 71, No. 5, 1992, pp. 1228-1237. doi:10.1177/00220345920710051601 
[4] K. F. Fung, Z. Q. Zhang, J. W. C. Wong and M. H. Wong, "Fluoride Contents in Tea and Soil from Tea Plantations and the Release of Fluoride into Tea Liquor during Infusion,” Environmental Pollution, Vol. 104, No. 2, 1999, pp. 197-205. doi:10.1016/S0269-7491(98)00187-0

[5] J. Cao, S. F. Luo, J. W. Liu and Y. H. Li, "Safety Evaluation on Fluoride Content in Black Tea," Food Chemistry, Vol. 88, No. 2, 2004, pp. 233-236. doi:10.1016/j.foodchem.2004.01.043

[6] G. M. Whitford, "The Metabolism and Toxicity of Fluo- ride,” Fluoride, Vol. 16, No. 2, 1997, p. 110.

[7] National Research Council, "Fluoride in Drinking Water: A Scientific Review of EPA's Standards,” National Academics Press, Washington DC, 2006.

[8] H. Klein and C. E. Palmer "Dental Caries in American Indian Children,” Public Health Bulletin, No. 239, 1937.

[9] M. C. Kiritsy, S. M. Levy, J. J. Warren, N. Guha-Chowdhary, "Assessing Fluoride Concentrations of Juices and Juice-Flavored Drinks,” Journal of American Dental Association, Vol. 127, No. 7, 1996, pp. 895-902. 